\title{
Peroxisome proliferator-activated receptor $\gamma$ polymorphisms as risk factors for dyslipidemia
}

\author{
SHU-JUN GU ${ }^{1,2}$, ZHI-RONG GUO ${ }^{2}$, ZHENG-YUAN ZHOU ${ }^{1}$, XIAO-SHU HU ${ }^{3}$, MING WU ${ }^{4}$ and NING ZHANG ${ }^{1}$ \\ ${ }^{1}$ Center for Disease Control of Changshu, Suzhou, Jiangsu 215500; ${ }^{2}$ Department of Epidemiology, \\ School of Public Health, Soochow University, Suzhou, Jiangsu 215123; ${ }^{3}$ Health Bureau of Jiangsu Province, \\ ${ }^{4}$ Center for Disease Control of Jiangsu Province, Nanjing, Jiangsu 210009, P.R. China
}

Received August 23, 2013; Accepted June 26, 2014

DOI: $10.3892 / \mathrm{mmr} .2014 .2553$

\begin{abstract}
Peroxisome proliferator-activated receptor $\gamma$ $(\operatorname{PPAR} \gamma)$ may play an important role in lipid metabolism directly or by inducing the transcription of target genes. The aim of the present study was to investigate the association between common variants at the PPAR $\gamma$ locus (C1431T and Pro12Ala polymorphisms) and lipid serum levels. The studied population consisted of 820 subjects randomly selected from the Prevention of Multiple Metabolic Disorders and Metabolic Syndrome in Jiangsu Province cohort population. All subjects were interviewed and blood samples were obtained for laboratory analysis and DNA extraction. The TaqMan single nucleotide polymorphism genotyping assay was used for polymorphism genotyping. Individual polymorphisms and haplotype data were available for analysis. The 12Ala allele was found to be associated with significantly increased levels of triglyceride $(\mathrm{TG})(\mathrm{P}<0.01)$, whilst the 1431T allele was found to be associated with significantly increased levels of TG, total cholesterol (TC) and non-high-density lipoprotein (non-HDL) $(\mathrm{P}<0.01)$. When $\mathrm{P}-\mathrm{C}$, the most common haplotype, was used as the reference group, the P-T, A-C and A-T haplotypes were found to be associated with significantly increased levels of TG $(\mathrm{P}<0.01)$. In addition, the A-T haplotype was shown to be associated with significantly increased levels of TC and non-HDL $(\mathrm{P}<0.01)$. In conclusion these results suggest that PPAR $\gamma$ gene variability may increase the risk of dyslipidemia.
\end{abstract}

Correspondence to: Dr Zhi-Rong Guo, Department of Epidemiology, School of Public Health, Soochow University, 199 Renai Road, Suzhou, Jiangsu 215123, P.R. China

E-mail: guozhirong28@163.com

Abbreviations: BMI, body mass index; CI, confidence interval; HDL, high-density lipoprotein; PPAR, peroxisome proliferator-activated receptor; LDL, low-density lipoprotein; LD, linkage disequilibrium; TG, triglyceride; TC, total cholesterol; non-HDL, non-high-density lipoprotein; WC, waist circumference

Key words: peroxisome proliferator-activated receptor, lipid, Pro12Ala, C1431T, haplotype

\section{Introduction}

Dyslipidemia is considered to be an important healthcare issue. It is well established that high levels of low-density lipoprotein (LDL), triglyceride (TG), total cholesterol (TC) and non-high-density lipoprotein (non-HDL) and low HDL levels are strong indicators for cardiovascular events (1). The exact cause of dyslipidemia has yet to be elucidated; however, it is known that genetics have an important role. Peroxisome proliferator-activated receptor $\gamma$ (PPAR $\gamma$ ) is a member of the nuclear hormone receptor superfamily. PPAR $\gamma$ is expressed at high levels in adipose tissue, where it plays a pivotal role in the regulation of adipocyte differentiation, glucose metabolism, lipid storage and the transcriptional regulation of certain genes associated with these processes. Common variants of the PPAR $\gamma$ gene have been described. The most studied of these is the substitution in exon $\mathrm{B}$, resulting in an alanine to proline conversion at codon 12 of PPAR $\gamma$ (Pro12Ala) (2). Another silent mutation in exon 6 of the PPAR $\gamma$ gene, C1431T, which has been studied in several populations, has been found to modulate the associations observed with the codon 12 substitution (3). Although it has previously been hypothesized that PPAR $\gamma$ may have either a direct role in lipid metabolism or an indirect role, by inducing the transcription of target genes $(4,5)$, few studies to date have investigated the association between PPAR $\gamma$ genetic variants and lipid profiles. Furthermore, the results from the available studies are inconsistent (1,6-9). Therefore, the aim of the present study was to investigate the association between common variants at the PPAR $\gamma$ locus (C1431T and Pro12Ala polymorphisms) and lipid serum levels.

\section{Materials and methods}

Study population. Participants were recruited from the Prevention of Multiple Metabolic Disorders and Metabolic Syndrome in Jiangsu Province study (10), which ran between April 1999 and June 2004. Five-year follow-up data for 4,582 subjects were obtained between March 2006 and October 2007. A total of 4,083 participants (89.11\%) received a follow-up examination (the patients who attended the follow-up examinations were similar to those lost from the follow-up cohort in terms of age, gender, smoking habits, alcohol intake, family disease history and metabolic variables; $\mathrm{P}>0.05$ ). Subjects who 
Table I. Description of the Pro12Ala and C161T polymorphisms.

\begin{tabular}{llccccr}
\hline SNP ID & SNP & Chromosome & Position & Exon/intron & Amino acid substitution & MAF $^{\mathrm{a}}$ \\
\hline rs1805192 & Pro12Ala & 3 & 12361238 & Exon-B & $\mathrm{C}>\mathrm{G}$ & 0.26 \\
rs3856806 & C1431T & 3 & 12415557 & Exon-6 & $\mathrm{C}>\mathrm{T}$ & 0.15 \\
\hline
\end{tabular}

${ }^{a} \mathrm{MAF}$ in the total group of this study. MAF, minor allele frequency; SNP, single nucleotide polymorphism; C, cysteine; G, glycine; T, threonine.

had suffered a stroke or exhibited cardiovascular disease $(n=36$, 11 of whom succumbed), type 2 diabetes $(n=289,31$ of whom succumbed), or had a body mass index (BMI) $<18.5 \mathrm{~kg} / \mathrm{m}^{2}(\mathrm{n}=27$, two of whom succumbed) were excluded, as well as those with missing data $(\mathrm{n}=133)$. A total of 820 unrelated individual subjects (270 males and 550 females) were selected from the remaining 3,731 cases using simple random sampling. Subjects that were selected were similar to those who were not selected, in terms of age, gender, smoking habits, alcohol intake, family disease history and metabolic variables. Blood samples were obtained from the 820 subjects as a baseline and subjected to genotype analysis. Lipid levels were measured at follow-up and were used to examine the association between PPAR $\gamma$ polymorphisms and lipid levels in the study population. All the participants signed informed consent forms. The study was approved by the Ethics Committee of Soochow University (Suzhou, China).

Body measurements and laboratory methods. Participants in the baseline and follow-up study surveys completed a standard questionnaire and physical measurements were collected, as well as blood samples after $\geq 8 \mathrm{~h}$ of fasting (which were used to detect and establish a cell library). The analysis methods used in the present study were the same as those in the baseline study. Cigarette smokers were those who reported smoking cigarettes at least once a day for $\geq 1$ year. Total alcohol intake was expressed as the total alcohol $(\mathrm{ml}) /$ week. Anthropometric measurements taken included body weight and waist circumference (WC), and BMI was calculated according to the Quetelet equation. Plasma glucose was measured using the oxidase enzymatic method and serum TC, HDL and TG levels were measured enzymatically. LDL-cholesterol concentrations were calculated using the Friedewald formula and the non-HDL level was calculated as the value of TC minus HDL. The measurements were performed using an automatic biochemistry analyzer (Hitachi Inc., Tokyo, Japan).

Genotyping. Genomic DNA from participants was extracted from EDTA-treated blood using the DNA Blood Mini kit (Qiagen, Hilden, Germany) in accordance with the manufacturer's instructions. The quality and quantity of isolated genomic DNA were verified using agarose gel electrophoresis and spectrophotometry, respectively. Single nucleotide polymorphism (SNP) genotyping was performed using the TaqMan SNP genotyping assay (Applied Biosystems, Shanghai, China). The primers and probes for the SNPs were obtained from the ABI Assay-on-Demand ${ }^{\text {TM }}$ kit (Applied Biosystems). Reactions were performed in accordance with the manufacturer's instructions. The fluorescent probe signal was detected using the ABI Prism 7000 Real-Time PCR System. Table I provides
Table II. General characteristics of the study population.

\begin{tabular}{lc}
\hline Variable & Value \\
\hline Total N (m/f) & $820(270 / 550)$ \\
Age, years & $50.05 \pm 9.41$ \\
Height, $\mathrm{cm}$ & $158.70 \pm 7.78$ \\
Weight, $\mathrm{kg}$ & $57.96 \pm 9.71$ \\
BMI, $\mathrm{kg} / \mathrm{m}^{2}$ & $22.83 \pm 3.12$ \\
WC $\mathrm{cm}$ & $77.62 \pm 9.05$ \\
Fasting glucose, $\mathrm{mmol} / \mathrm{l}$ & $5.01 \pm 0.75$ \\
Triglycerides, $\mathrm{mmol} / \mathrm{l}$ & $1.40 \pm 0.59$ \\
Total cholesterol, $\mathrm{mmol} / \mathrm{l}$ & $4.91 \pm 1.11$ \\
LDL, $\mathrm{mmol} / \mathrm{l}$ & $1.35 \pm 0.41$ \\
HDL, $\mathrm{mmol} / \mathrm{l}$ & $1.29 \pm 0.30$ \\
Non-HDL, $\mathrm{mmol} / \mathrm{l}$ & $2.92 \pm 1.00$
\end{tabular}

Results, with the exception of total N, are presented as the mean \pm standard deviation. BMI, body mass index; WC, waist circumference; LDL, low-density lipoprotein; HDL, high-density lipoprotein; m, male, $f$, female.

information on the selected SNPs, including their features, allelic variants and the minor allele frequencies.

Statistical analysis. The mean and standard deviation were calculated for normally distributed continuous variables. PPAR $\gamma$ genotype distributions for participants were assessed for adherence to the Hardy-Weinberg equilibrium using the $\chi^{2}$ test. Mann-Whitney or Student's t-tests were performed to verify the association between the polymorphisms and the serum lipid levels or lipid fractions. Line regression analysis was then performed to verify the association using gender, age, smoking habits, alcohol consumption, BMI, WC and fasting glucose as covariates in the model. Differences and 95\% confidence intervals (CI) were also calculated. PA and AA genotype carriers for the Pro12Ala polymorphism and CT and TT genotype carriers for the C1431T polymorphism were grouped together due to a low number of AA/TT homozygotes in this sample. Data analysis of individual polymorphisms was performed using SPSS 13.0 (SPSS, Inc., Chicago, IL, USA). Estimation of linkage disequilibrium (LD) between polymorphisms was performed using SHEsis software (http://analysis2.bio-x.cn/SHEsisMain. htm). LD between Pro12Ala and C1431T polymorphisms was measured by D' using SHEsis software. Haplotype association analysis was performed using the SNPStats web tool (http:// bioinfo.iconcologia.net/SNPstats_web). 
Table III. Association between the Pro12Ala polymorphism and lipid values.

\begin{tabular}{|c|c|c|c|c|c|}
\hline \multirow[b]{2}{*}{ Variable } & \multicolumn{2}{|c|}{ Pro12Ala } & \multirow[b]{2}{*}{ P-value } & \multirow[b]{2}{*}{ Difference $(95 \% \mathrm{CI})$} & \multirow[b]{2}{*}{ P-value } \\
\hline & $\mathrm{PP}$ & A & & & \\
\hline $\mathrm{N}$ & 459 & 361 & & & \\
\hline Triglycerides, mmol/l & $1.94 \pm 1.80$ & $2.95 \pm 2.22$ & $<0.01$ & $0.86(0.59-1.14)$ & $<0.01$ \\
\hline Total cholesterol, mmol/l & $4.10 \pm 1.16$ & $4.21 \pm 1.07$ & 0.16 & $0.09(-0.07-0.25)$ & 0.27 \\
\hline $\mathrm{LDL}, \mathrm{mmol} / \mathrm{l}$ & $1.35 \pm 0.43$ & $1.33 \pm 0.39$ & 0.51 & $-0.01(-0.07-0.04)$ & 0.61 \\
\hline HDL, mmol/1 & $1.24 \pm 0.37$ & $1.22 \pm 0.36$ & 0.45 & $-0.02(-0.07-0.03)$ & 0.40 \\
\hline Non-HDL, mmol/1 & $2.86 \pm 1.03$ & $2.99 \pm 0.95$ & 0.07 & $0.13(-0.01-0.27)$ & 0.12 \\
\hline
\end{tabular}

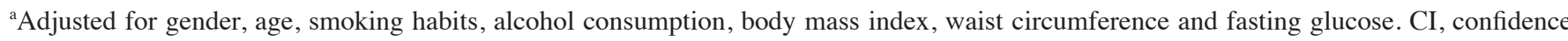
interval; LDL, low-density lipoprotein; HDL, high-density lipoprotein; P, proline; A, alanine.

Table IV. Association between the C1431T polymorphism and lipid values.

\begin{tabular}{|c|c|c|c|c|c|}
\hline \multirow[b]{2}{*}{ Variable } & \multicolumn{2}{|c|}{$\mathrm{C} 1431 \mathrm{~T}$} & \multirow[b]{2}{*}{$\mathrm{P}$-value } & \multirow[b]{2}{*}{ Difference $(95 \% \mathrm{CI})$} & \multirow[b]{2}{*}{ P-value ${ }^{a}$} \\
\hline & $\mathrm{CC}$ & $\mathrm{T}$ & & & \\
\hline $\mathrm{N}$ & 418 & 402 & & & \\
\hline Triglycerides, mmol/1 & $2.03 \pm 1.77$ & $2.75 \pm 2.27$ & $<0.01$ & $0.58(0.31-0.85)$ & $<0.01$ \\
\hline Total cholesterol, mmol/l & $4.03 \pm 1.14$ & $4.27 \pm 1.09$ & $<0.01$ & $0.24(0.08-0.39)$ & $<0.01$ \\
\hline $\mathrm{LDL}, \mathrm{mmol} / \mathrm{l}$ & $1.34 \pm 0.43$ & $1.35 \pm 0.39$ & 0.14 & $-0.07(-0.21-0.07)$ & 0.36 \\
\hline $\mathrm{HDL}, \mathrm{mmol} / \mathrm{l}$ & $1.22 \pm 0.39$ & $1.24 \pm 0.33$ & 0.28 & $0.04(-0.01-0.09)$ & 0.10 \\
\hline Non-HDL, mmol/1 & $2.81 \pm 0.98$ & $3.03 \pm 1.00$ & $<0.01$ & $0.20(0.06-0.33)$ & $<0.01$ \\
\hline
\end{tabular}

${ }^{a}$ Adjusted for gender, age, smoking, alcohol consumption, body mass index, waist circumference and fasting glucose. CI, confidence interval; LDL, low-density lipoprotein; HDL, high-density lipoprotein; C, cysteine; T, threonine.

\section{Results}

Table II shows the characteristics of the studied population. A total of 820 individuals were genotyped for Pro12Ala and C161T polymorphisms. The allele frequencies of 12Ala and $1431 \mathrm{~T}$ were 0.26 and 0.15 , respectively. The polymorphisms were in Hardy-Weinberg equilibrium $(\mathrm{P}=0.06$ and $\mathrm{P}=0.38$, respectively for Pro12Ala and $\mathrm{C} 161 \mathrm{~T}$ polymorphisms). Linkage analysis showed modest but significant LD between these polymorphisms $\left(\mathrm{D}^{\prime}=0.196 ; \mathrm{r}^{2}=0.004 ; \mathrm{P}=0.013\right)$.

The single SNP association analysis showed that the 12Ala allele was associated with significantly increased levels of TG $(\mathrm{P}<0.01)$, even following adjustment for gender, age, smoking, alcohol consumption, BMI, WC and fasting glucose (difference, 0.86; 95\% CI, 0.59-1.14; $\mathrm{P}<0.01$ ) (Table III). In addition, the $1431 \mathrm{~T}$ allele was associated with significantly increased levels of TG, TC and non-HDL ( $\mathrm{P}<0.01)$, even following adjustment for the same variables as above [(difference, $0.58 ; 95 \% \mathrm{CI}, 0.31-0.85$; $\mathrm{P}<0.01$ ); (difference, 0.24, 95\% CI, 0.08-0.39; $\mathrm{P}<0.01$ ); (difference, 0.20; 95\% CI, 0.06-0.33; $\mathrm{P}<0.01$ ), respectively] (Table IV). No significant association was found between the Pro12Ala or C1431T polymorphisms and LDL or HDL levels ( $\mathrm{P}>0.05)$.

Haplotype association analysis showed that when the most common haplotype $\mathrm{P}-\mathrm{C}$ was treated as the reference group, the P-T, A-C and A-T haplotypes were associated with significantly increased levels of TG [(difference, $0.60 ; 95 \%$ CI, 0.32-0.88; $\mathrm{P}<0.01$ ); (difference, 0.87; 95\% CI, 0.58-1.17; $\mathrm{P}<0.01$ ); (difference, 0.94; 95\% CI, 0.57-1.30; $\mathrm{P}<0.01$ ), respectively]. In addition, the A-T haplotype was associated with significantly increased levels of TC and non-HDL [(difference, 0.29; 95\% CI, 0.09-0.48; P<0.01); (difference, 0.27; 95\% CI, 0.09-0.44; $\mathrm{P}<0.01$ ), respectively)] (Table V).

\section{Discussion}

In the present study, the association between two common polymorphisms within the PPAR $\gamma$ gene and lipid serum levels, including TG, TC and LDL plasma levels, was investigated. The single SNP association analysis showed that the 12Ala allele was associated with significantly increased levels of TG $(\mathrm{P}<0.01)$, whilst the 1431T allele was associated with significantly increased levels of TG, TC and non-HDL $(\mathrm{P}<0.01)$. The most common haplotype $\mathrm{P}-\mathrm{C}$ was then treated as the reference group and it was found that the P-T, A-C and A-T haplotypes were associated with significantly increased levels of TG $(\mathrm{P}<0.01)$. In addition, the A-T haplotype was associated with significantly increased levels of TC and non-HDL $(\mathrm{P}<0.01)$. These results suggest that PPAR $\gamma$ gene variability may increase the risk of dyslipidemia.

A number of previous studies have found that Pro12Ala and C1431T polymorphisms are associated with obesity, insulin 
Table V. Haplotypes of peroxisome proliferator-activated receptor $\gamma$ Pro12Ala and C1431T polymorphisms and association with triglyceride, total cholesterol and non-HDL levels.

\begin{tabular}{lccccc}
\hline Variable & Pro12Ala & C1431T & Frequency & Difference (95\% CI) & P-value $^{\mathrm{a}}$ \\
\hline Triglyceride & P & $\mathrm{C}$ & 0.539 & 0 & - \\
& $\mathrm{P}$ & $\mathrm{T}$ & 0.196 & $0.60(0.32-0.88)$ & $<0.01$ \\
& $\mathrm{~A}$ & $\mathrm{C}$ & 0.170 & $0.87(0.58-1.17)$ & $<0.01$ \\
Total cholesterol & $\mathrm{A}$ & $\mathrm{T}$ & 0.095 & $0.94(0.57-1.30)$ & $<0.01$ \\
& $\mathrm{P}$ & $\mathrm{C}$ & 0.5395 & 0 & - \\
& $\mathrm{P}$ & $\mathrm{T}$ & 0.1959 & $0.15(0.00-0.30)$ & 0.06 \\
Non-HDL & $\mathrm{A}$ & $\mathrm{C}$ & 0.1691 & $0.09(-0.07-0.25)$ & 0.29 \\
& $\mathrm{~A}$ & $\mathrm{~T}$ & 0.0956 & $0.29(0.09-0.48)$ & $<0.01$ \\
& $\mathrm{P}$ & $\mathrm{C}$ & 0.5395 & 0 & - \\
& $\mathrm{P}$ & $\mathrm{T}$ & 0.1959 & $0.13(-0.01-0.26)$ & 0.07 \\
& $\mathrm{~A}$ & $\mathrm{C}$ & 0.1691 & $0.11(-0.03-0.25)$ & 0.12 \\
& $\mathrm{~A}$ & $\mathrm{~T}$ & 0.0956 & $0.27(0.09-0.44)$ & $<0.01$ \\
\hline
\end{tabular}

${ }^{a}$ Adjusted for gender, age, smoking, alcohol consumption, body mass index, waist circumference and fasting glucose. HDL, high-density lipoprotein; $\mathrm{CI}$, confidence interval; $\mathrm{P}$, proline; $\mathrm{C}$, cysteine; T, threonine; A, alanine.

sensitivity and type 2 diabetes (11-13). However, few studies have been conducted on the association between Pro12Ala or C1431T polymorphisms and lipid serum levels in the general population $(14,15)$, and the conclusions from these studies are contradictory $(6,8,14-18)$. Barbieri et al (8) found that in 429 Caucasian subjects, the Ala12 allele was inversely associated with blood TG concentrations. The Ala12 allele has also been shown to be associated with lower levels of total HDL and non-HDL in the serum of a Japanese population (14), lower LDL in patients with type 2 diabetes (17) and higher levels of serum HDL-cholesterol in family-based or population-based studies $(16,15)$. In obese individuals, Swarbrick et al (6) found that Pro12Ala was associated with increased TG levels and significantly associated with the presence of combined hyperlipidemia. In a group of 57 obese males, Beamer et al (18) found that Pro12Ala was associated with an increase in TG levels. It was found in the present study that, following correction for age, gender, smoking habits, alcohol consumption, BMI, WC and fasting glucose, there was a significant association between the 12Ala allele and higher TG levels $(\mathrm{P}<0.01)$. The discrepancies in the available data may be due to differences in ethnicity and the selection of subjects.

In the present study it was shown that, following correction for age, gender, smoking habits, alcohol consumption, BMI, WC and fasting glucose, subjects carrying the $1431 \mathrm{~T}$ allele had significantly higher TG, TC and non-HDL levels $(\mathrm{P}<0.01)$. A previous study by Zhou et al (19) found that the C1431T polymorphism was associated with higher HDL cholesterol levels and a lower blood glucose level in patients with coronary artery disease. In patients with coronary heart disease (CHD) and diabetes, Yilmaz-Aydogan et al (9) found that CT heterozygotes of the C161T polymorphism exhibited higher serum TG and very-low-density lipoprotein-cholesterol concentrations compared with the $\mathrm{CC}$ homozygotes. This may be due to fact that the sample comprised selected patients as opposed to being a random population-based sample.
Association studies with haplotypes comprising the information content of multilocus SNPs are considered more robust and allow the desirable approach of delineating the genetic basis of complex traits (20). A haplotype analysis investigating Pro12Ala and C1431T polymorphisms demonstrated a significant association between TG, TC and non-HDL levels and the polymorphisms. Carriers of the P-T, A-C and A-T haplotypes showed higher TG levels compared with the P-C haplotype carriers [(difference, 0.60; 95\% CI, 0.32-0.88; P<0.01); (difference, 0.87; 95\% CI, 0.58-1.17; P<0.01); (difference, 0.94; 95\% CI, $0.57-1.30 ; \mathrm{P}<0.01)$, respectively]. In addition, carriers of the A-T haplotype showed higher TC and non-HDL levels [(difference, 0.29; 95\% CI, 0.09-0.48; P<0.01); (difference, 0.27; 95\% CI, $0.09-0.44 ; \mathrm{P}<0.01)$, respectively]. To date, and to the best of our knowledge, a haplotype analysis investigating the association between Pro12Ala and C1431T polymorphisms for dyslipidemia, has only been reported in our previous study. In our previous study, the haplotypes (established by Pro12Ala and C1431T) were shown to be associated with dyslipidemia, and higher TC and TG levels (21). Yilmaz-Aydogan et al (9) found that serum TG levels were elevated in P12P-CC/P12P-CT/P12A-CC/P12A-CT genotype combinations in patients with $\mathrm{CHD}$ and diabetes. In the present study, as well as analyzing the association between the Pro12Ala and C1431T polymorphisms and lipid levels, the potential biological mechanism was investigated.

PPAR $\gamma$ is expressed at high levels in adipose tissue, where it plays a pivotal role in the regulation of adipocyte differentiation, glucose metabolism, lipid storage and the transcriptional regulation of certain genes associated with these processes. The key target genes of PPAR $\gamma$ include the fat-specific ap2 gene, lipoprotein lipase (LPL), fatty acid transport, fatty acid binding protein and ATP-binding cassette A1 (ABC-A1). LPL is an important enzyme that degrades $\mathrm{TG}$, whilst $\mathrm{ABC}-\mathrm{A} 1$ effectively regulates cellular cholesterol metabolism $(2,22)$. In vivo and in vitro assays have suggested that the PPAR $\gamma$ variants investigated in the present study have a functional impact. Deeb et al (23) found that the 12Ala allele showed a decreased binding affinity 
to the cognate promoter element and a reduced ability to transactivate responsive promoters. Additionally, a previous study showed that C1431T modulated the associations observed with the codon 12 substitution (3). We hypothesized that Pro12Ala and C1431T polymorphisms also had the potential to affect the regulation of lipid metabolism. The results from the haplotype analysis demonstrated that certain haplotypes were significantly associated with higher TG, TC and non-HDL levels and lipid metabolism. The specific biological mechanism, however, requires further investigation.

One limitation of the present study is that the findings may not be transferable to other populations. Large ethnically matched studies are necessary to elucidate whether such associations are found in non-Chinese Han individuals. Furthermore, information on physical factors, including lifestyle and dietary habits, that may affect PPAR $\gamma$ genotypes or act as potential confounding factors were not available in the study.

In conclusion, single-locus and haplotype analyses were used in the present study to investigate the association between two common variants at the PPAR $\gamma$ locus and lipid serum levels. The presented results may enhance the understanding of the role of the PPAR $\gamma$ gene in lipid and lipoprotein metabolism and enable the elucidation of its polymorphisms and haplotypes as genetic risk factors for dyslipidemia. Independent replications of this study with larger sample sizes are required in order to confirm the effect of the polymorphisms and haplotypes identified in this study on lipid metabolism. Physical risk factors should also be investigated in future studies.

\section{Acknowledgements}

This study was funded by the grants from the Scientific Research Fund of National Ministry of Health, Republic of China (WKJ 2004-2-014) and the Priority Academic Program Development of Jiangsu Higher Education Institutions. The authors would like to thank the medical staff and all participants, in particular those who supported this study by providing a blood sample.

\section{References}

1. Cullen P: Evidence that triglycerides are an independent coronary heart disease risk factor. Am J Cardiol 86: 943-949, 2000.

2. Azhar S: Peroxisome proliferator-activated receptors, metabolic syndrome and cardiovascular disease. Future Cardiol 6: 657-691, 2010.

3. Wu MH, Chu CH, Chou YC, Chou WY, Yang T, Hsu GC, Yu CP, Yu JC and Sun CA: Joint effect of peroxisome proliferator-activated receptor $\gamma$ genetic polymorphisms and estrogen-related risk factors on breast cancer risk: results from a case-control study in Taiwan. Breast Cancer Res Treat 127 777-784, 2011

4. Schoonjans K, Staels B and Auwerx J: Role of the peroxisome proliferator-activated receptor (PPAR) in mediating the effects of fibrates and fatty acids on gene expression. J Lipid Res 37: 907-925, 1996.

5. Chawla A, Barak Y, Nagy L, Liao D, Tontonoz P and Evans RM: PPAR-gamma dependent and independent effects on macrophage-gene expression in lipid metabolism and inflammation. Nat Med 7: 48-52, 2001.

6. Swarbrick MM, Chapman CM, McQuillan BM, Hung J, Thompson PL and Beilby JP: A Pro12Ala polymorphism in the human peroxisome proliferator-activated receptor-gamma 2 is associated with combined hyperlipidaemia in obesity. Eur J Endocrinol 144: 277-282, 2001.
7. Tavares V, Hirata RD, Rodrigues AC, Monte O, Salles JE, Scallissi N, Speranza AC, Gomes S and Hirata MH: Effect of the peroxisome proliferator-activated receptor-gamma C161T polymorphism on lipid profile in Brazilian patients with Type 2 diabetes mellitus. J Endocrinol Invest 28: 129-136, 2005.

8. Barbieri M, Rizzo MR, Papa M, Acampora R, De Angelis L, Oliviri F, Marchegiani F, Franceschi C and Paolisso G: Role of interaction between variants in the PPARG and interleukin-6 genes on obesity related metabolic risk factors. Exp Gerontol 40: 599-604, 2005.

9. Yilmaz-Aydogan H, Kurnaz O, Kurt O, Akadam-Teker B Kucukhuseyin O, Tekeli A and Isbir T: Effects of the PPARG $\mathrm{P} 12 \mathrm{~A}$ and C161T gene variants on serum lipids in coronary heart disease patients with and without Type 2 diabetes. Mol Cell Biochem 358: 355-363, 2011.

10. Hu XS, Guo ZR, Zhou H, Shi ZM, Wu M, Zhang J, Sun GX, ZhouZY,Pan XQ and Yao CL: Study on the prevalence of metabolic syndrome among 35-74 year-olds in Jiangsu province. Zhonghua Liu Xing Bing Xue Za Zhi 27: 751-756, 2006 (In Chinese).

11. Clement K, Hercberg S, Passinge B, Galan P, Varroud-Vial M, Shuldiner AR, Beamer BA, Charpentier G, Guy-Grand B, Froguel P and Vaisse C: The Pro115Gln and Pro12Ala PPAR gamma gene mutations in obesity and type 2 diabetes. Int J Obes Relat Metab Disord 24: 391-393, 2000.

12. Hara K, Okada T, Tobe K, Yasuda K, Mori Y, Kadowaki H, Hagura R, Akanuma Y, Kimura S, Ito C and Kadowaki T: The Pro12Ala polymorphism in PPAR gamma 2 may confer resistance to type 2 diabetes. Biochem Biophys Res Commun 271: 212-216, 2000.

13. Doney A, Fischer B, Frew D, Cumming A, Flavell DM, World M, Montgomery HE, Boyle D, Morris A and Palmer CN: Haplotype analysis of the PPARgamma Pro12Ala and C1431T variants reveals opposing associations with body weight. BMC Genet 3: 21, 2002.

14. Iwata E, Matsuda H, Fukuda T, Fukuen S, Motomura T, Igarashi T, Yamamoto I and Azuma J: Mutations of the peroxisome proliferator-activated receptor gamma (PPARgamma) gene in a Japanese population: the Pro12Ala mutation in PPAR gamma 2 is associated with lower concentrations of serum total and non-HDL cholesterol. Diabetologia 44: 1354-1355, 2001

15. Tai ES, Corella D, Deurenberg-Yap M, Adiconis X, Chew SK, Tan CE and Ordovas JM: Differential effects of the C1431T and Pro12Ala PPARgamma gene variants on plasma lipids and diabetes risk in an Asian population. J Lipid Res 45: 674-685, 2004

16. Brand-Herrmann SM, Kuznetsova T, Wiechert A, Stolarz K, Tikhonoff V, Schmidt-Petersen K, Telgmann R, Casiglia E, Wang JG, Thijs L, Staessen JA and Brand E; European Project on Genes in Hypertension Investigators: Alcohol intake modulates the genetic association between HDL cholesterol and the PPARgamma2 Pro12Ala polymorphism. J Lipid Res 46: 913-919, 2005.

17. Pollex RL, Mamakeesick M, Zinman B, Harris SB, Hegele RA and Hanley AJ: Peroxisome proliferator-activated receptor gamma polymorphism Pro12Ala is associated with nephropathy in type 2 diabetes. J Diabetes Complications 21: 166-171, 2007.

18. Beamer BA, Yen CJ, Andersen RE, Muller D, Elahi D, Cheskin LJ, Andres R, Roth J and Shuldiner AR: Association of the Pro12Ala variant in the peroxisome proliferator-activated receptor-gamma2 gene with obesity in two Caucasian populations. Diabetes 47: 1806-1808, 1998

19. Zhou X, Chen J and Xu W: Association between C1431T polymorphism in peroxisome proliferator-activated receptor- $\gamma$ gene and coronary artery disease in Chinese Han population. Mol Biol Rep 39: 1863-1868, 2012.

20. Patil N, Berno AJ, Hinds DA, Barrett WA, Doshi JM, Hacker CR, Kautzer CR, Lee DH, Marjoribanks C, McDonough DP, Nguyen BT, Norris MC, Sheehan JB, Shen N, Stern D, Stokowski RP, Thomas DJ, Trulson MO, Vyas KR, Frazer KA, Fodor SP and Cox DR: Blocks of limited haplotype diversity revealed by high-resolution scanning of human chromosome 21 . Science 294: 1719-1723, 2001.

21. Gu SJ, Guo ZR, Zhou ZY, Hu XS and Wu M: PPAR $\alpha$ and PPAR $\gamma$ polymorphisms as risk factors for dyslipidemia in a Chinese Han population. Lipids Health Dis 13: 23, 2014

22. Semple RK, Chatterjee VK and O'Rahilly S: PPAR gamma and human metabolic disease. J Clin Invest 116: 581-589, 2006.

23. Deeb SS, Fajas L, Nemoto M, Pihlajamäki J, Mykkänen L, Kuusisto J, Laakso M, Fujimoto W and Auwerx J: A Pro12Ala substitution in PPARgamma2 associated with decreased receptor activity, lower body mass index and improved insulin sensitivity. Nat Genet 20: 284-287, 1998. 